\title{
Irritable bowel syndrome, food intolerance and non- celiac gluten sensitivity. A new clinical challenge
}

\author{
Rosa Leonôra Salerno SOARES
}

Received 21/9/2018

Accepted 23/10/2018

\begin{abstract}
Approximately $80 \%$ of irritable bowel syndrome (IBS) patients report that their symptoms are triggered after ingesting one or specific food groups. Gluten, wheat and related proteins (e.g., amylase-trypsin inhibitors, and fermentable oligo-di-mono-saccharides and polyols (FODMAPs) are the most relevant IBS symptom triggers, although the true 'culprit(s)' is/are still not well established. The concept of causal relationship between gluten intake and the occurrence of symptoms in the absence of celiac disease and wheat allergy was termed non-celiac gluten sensitivity (NCGS). The borderline between celiac disease, wheat allergy, IBS and NCGS is not always clearly distinguishable, and the frequency and clinical identity of NGCS are still unclear. An overlap between IBS and NCGS has been detected. The incomplete knowledge of the etiopathogenesis of these clinical conditions, lack of data on their real epidemiology, as well as the absence of a gold standard for their diagnosis, make the overall picture difficult to understand "It is crucial to well define the interaction between IBS, food intolerance and NGCS, since the role of diet in IBS and its dietary management is an essential tool in the treatment of a large number of these patients". The objective of the present review is to provide an overview highlighting the interaction between IBS, food intolerance and NCGS in order to unravel whether gluten/wheat/FODMAP sensitivity represents 'facts' and not 'fiction' in IBS symptoms.
\end{abstract}

HEADINGS - Irritable bowel syndrome. Food intolerance. Celiac disease. Wheat hypersensitivity.

\section{INTRODUCTION}

Irritable bowel syndrome (IBS) is a functional bowel disorder and one of the most commonly diagnosed gastrointestinal diseases with a global estimated prevalence of $10 \%-20^{\%} \%^{(1-5)}$. This percentage varies with the methodology used in the studies and with the geographic area evaluated. Characterized by recurrent symptoms, it has no biological markers available for its diagnosis and approximately $80 \%$ of IBS patients report that their symptoms are triggered after ingesting one or specific food groups. Today IBS diagnosis is based on Rome IV criteria ${ }^{(6,7)}$. Clinical criteria known as Roma criteria are those used for the diagnosis of functional digestive disease, including $\mathrm{IBS}^{(8-10)}$. Although they are criteria under construction and updated since its first edition in 1990, most gastroenterologists do not use them for daily clinical practice, and their use is often reserved for research projects. These data help us understand both the difficulties of homogenizing samples for clinical research and the universalization of the clinical-epidemiological and diagnostic-therapeutic aspects of patients with IBS. In addition, a large number of patients exhibit the mild form of the disease and never seek medical services, which also makes it difficult to study the natural history of the disease $e^{(1,9,11-13)}$. The pathogenesis of IBS is multifactorial ${ }^{(14-20)}$. However, the triggering factors of IBS symptoms may be present in different combinations for each patient. However, it is not clear how these factors act as triggers in the generation of symptoms associated with $\operatorname{IBS}^{(12,18-20)}$. The heterogeneous pathogenesis of IBS could lead to alterations in motility, visceral sensation, brain-intestinal interactions, microbiome, bile acid metabolism and intestinal permeability. In addition, an immune activation is probably involved in low-grade inflammation $^{(14,15,18,19)}$. Given the complexity of its pathophysiology and the clinical subgroups resulting from this umbrella of options, IBS is considered to be a gastrointestinal-brain disorder and is clinically defined as a biopsychosocial disease ${ }^{(12,20)}$. A significant number of IBS patients report the onset of symptoms after ingesting one or specific food groups ${ }^{(1,9,11-13)}$. The most frequent ones are those that present lactose, fructose in excess of glucose, fructan, galactooligosaccharides and polyols ${ }^{(21-26)}$. In addition, it has recently been reported that a percentage of patients with a negative diagnosis for celiac disease reported that foods containing gluten triggered the symptoms of IBS. This association is included in the concept of IBS-like disorders ${ }^{(27-36)}$. A subset of patients diagnosed with IBS report worsening symptoms when they eat foods that contain gluten and improve with the withdrawal of these foods from the diet. However, most of these patients report intolerance and worsening of symptoms to other nutrients in their $\operatorname{diet}^{(37,38)}$. The new clinical entity still without specific clinical contour was denominated of non-celiac gluten sensitivity (NCGS), related to sensitivity to the wheat and the gluten, and has aroused so much the interest of the scientific community as of the population in general. Its clinical

Declared conflict of interest of all authors: none

Disclosure of funding: no funding received

Universidade Federal Fluminense, Faculdade de Medicina, Departamento de Medicina Interna, Niterói, RJ, Brasil.

Corresponding author: Rosa Leonôra Salerno Soares. Orcid: https://orcid.org/0000-0002-2858-1922. E-mail: rosaleonora@gmail.com 
picture is similar to that of patients with IBS. The overlap of IBS with NCGS gave rise to a large number of pathophysiological theories that could influence the therapeutic management of patients with IBS who report food intolerance and the appearance of symptoms after eating foods containing gluten, improving with the withdrawal of these foods from the diet ${ }^{39-42}$. The overlap between IBS and NCGS gave rise to a large number of pathophysiological theories that influence the therapeutic management of patients with IBS who report food intolerance and the onset of symptoms after eating gluten-containing foods and improve with the withdrawal of these foods from the diet. Although it may be described as a new subgroup of patients with IBS, most of these patients report intolerance and worsening symptoms to other nutrients in their $\operatorname{diet}^{(12,43-45)}$. The objective of the present review is to provide an overview highlighting the interaction between IBS, food intolerance and NCGS in order to unravel whether gluten/wheat/fermentable oligo-di-mono-saccharides and polyols (FODMAPs) sensitivity represents 'facts' and not 'fiction' in IBS symptoms.

\section{IBS and food intolerance}

Approximately $80 \%$ of IBS patients report that their symptoms are triggered by at least one food item and they increasingly ask for dietary and behavioral counseling ${ }^{(6,12,13,17,21,22,28,29)}$. In recent years, (fermentable oligosaccharides, disaccharides, monosaccharides, polyols) and gluten/wheat have been increasingly recognized as a possible trigger for symptoms compatible with a diagnosis of $\mathrm{IBS}^{(38,39)}$. The mechanisms of food intolerance in IBS remain unknown ${ }^{(14,18,21,23,25,28)}$. These triggering foods do not reflect food allergies or even IgE-mediated classical food allergy seems to play an important role in IBS ${ }^{(21-23,30-33,46-48)}$. Wheat has been considered a frequent trigger in the genesis of IBS-associated symptoms. However, the component (s) of this cereal that is directly involved in generating the symptoms of IBS remains unknown. Gluten, other wheat proteins, for example, amylase-trypsin inhibitors and fructans (the latter belonging to FODMAPs) have been identified as possible factors for the generation and or exacerbation of IBS symptoms $^{(27,28,37-39,40-43,48)}$. Symptoms related to FODMAPs share the same clinical characteristics associated with lactose intolerance and many foods rich in FODMAPs are also rich in lactose. Because of the high prevalence of lactose intolerance, it is not surprising that a diet that is poor in FODMAPs can reduce or even resolve gastrointestinal and extra-intestinal symptoms ${ }^{(49-51)}$. An important intersection exists between FODMAPs and NCGS. Thus, after a more detailed evaluation, symptoms associated with IBS could be triggered by FODMAPs and not by gluten itself. The same thing can be true for foods rich in Ni, very numerous in the FODMAPs family, such as pears, cabbage, garlic, onion and legumes. Multiple factors have been considered to contribute to food sensitivity in patients with IBS. Investigations have centered on food specific antibodies, carbohydrate malabsorption, and gluten sensitivity. Although some IBS patients related relief of symptoms on a gluten-free diet the specific relationship between gluten and increased intestinal permeability in IBS have not yet confirmed. We reported that IBS patients have difficulties with food in general and specific foods may not be involved in IBS pathogenesis. It is reasonable to assume that IBS causes food sensitivity, rather than vice versa ${ }^{(12,18,21,22,28,32,38,39,43,46)}$. The mechanisms involved in the pathophysiological alterations found in IBS seem to be multiple and are still uncertain. A unifying hypothesis for the generation of these symptoms would be the phenomenon of visceral hypersensitivity identified in most of the patients with IBS $^{(21-23,30-33,46-48)}$. The phenomenon of visceral hypersensitivity may be related to an increased response of the neuroimmune circuits in the nervous system or gastrointestinal tract to external stimuli (for example environmental or psychosocial stimuli) or internal ones (tissue irritation, inflammation, infection). This increased response may result in abnormalities of digestive motility, inducing symptoms compatible with the clinical picture of IBS $^{(12,14,15,18,21,23,33)}$. In synthesis, an abnormal neuroimmune interaction (genetic and psychosocial factors, food intolerance, and bacterial microflora) may contribute to the phenomenon of visceral hypersensitivity frequently observed in the patients with IBS. This finding suggests that patients with IBS symptoms have difficulties with foods in general. It is very probable that IBS causes food intolerance and not the opposite ${ }^{(12,15,16,31,41,43)}$.

\section{III- Gluten Related Disorders -NCGS and IBS}

Although mankind has existed for more than 2.5 million years, only in the last 10000 years have we been exposed to wheat and increased its production exponentially. By the end of the twentieth century, wheat production increased fivefold ${ }^{(52)}$. This would be an explanation for the change in the epidemiology of celiac disease or gluten-sensitive enteropathy and the significant increase in the number of scientific publications regarding celiac disease (CD) and other related non celiac gluten sensitivity (NCGS) $)^{(43-45,47,50,51-53)}$. The increase in the global prevalence of celiac disease may be true or associated with an increase in the number of diagnostic serological tests. In the case of NCGS, the increase in prevalence could be associated with an increase in global wheat consumption in the last decades ${ }^{(27,35,36,37,54)}$. The varied food forms of wheat contain more gluten than in the past and could be associated with digestive symptoms ${ }^{(52,53)}$. The concept of a causal relationship between the ingestion of gluten and the occurrence of symptoms in absence of CD and wheat allergy was first described in the late 1970s by Cooper and Ellis ${ }^{(55,56)}$. This clinical entity has been termed NCGS or NCWS. NCGS, the most famous of the GRDS and considered an adverse reaction to gluten, was recently "rediscovered" as a clinical entity without available diagnostic biomarkers. As defined by the Salerno Expert's Criteria NCGS is characterized by intestinal and extra-intestinal symptoms triggered by ingestion of gluten ${ }^{(57,58)}$. This association reported by some individuals has led to the spontaneous restriction of the consumption of foods containing gluten. Some authors report that NCGS has been described in $6 \%-10 \%$ of the population ${ }^{(53,57,58)}$. In contrast to allergy to wheat and celiac disease, its immunopathological process is not yet understood. Over $75 \%$ of these patients have HLA-DQ2 and / or HLA-DQ8.75\% of these patients carry HLA-DQ2 and/ or HLA-DQ8 ${ }^{(43)}$. NCGS can be defined to describe individuals who complain of intestinal and extra-intestinal symptoms related to gluten intake and report rapid improvement after withdrawal of these foods from the diet, and in which both the diagnosis of $\mathrm{CD}$ and wheat allergy are discarded $\mathrm{d}^{(4,52,53,58,59-73)}$. This fact raises many unanswered questions. NCGS exist?, how it induces digestive symptoms this group of individuals is nonspecific. The most common symptoms are diarrhea, bloating and abdominal pain. The definition of NGCS has many similarities with IBS ${ }^{(43-45,52)}$. Historically, it has been reported that patients with undetected celiac disease (CD) may present with IBS type symptoms. An overlap between IBS and NCGS has been detected. However, incomplete knowledge of the etiopathogenesis of these clinical 
conditions, lack of data on their real epidemiology, as well as the absence of a gold standard for their diagnosis, make the overall picture difficult to understand ${ }^{(22,27-28,34-37,44,45,57,58,61-63)}$. Gluten, wheat and related proteins (e.g., amylase-trypsin inhibitors, and fermentable oligo-di-mono-saccharides and polyols (FODMAPs) are the most relevant IBS symptom triggers, although the true 'culprit(s)' is/are still not well established ${ }^{(52,61,63,68,72,73)}$. In addition, Rome IV criteria seem unable to exclude an underlying possible IBS-like disorder. The lack of specific biomarkers hampers diagnosis of both conditions ${ }^{(6-10)}$. There is some evidence that the NCGS may exist, but probably only in a small number of people. In contrast to celiac disease, patients with self-reported NCGS are heterogeneous and suggestible by media advertising and food therapies without scientific evidence, which makes them a very difficult group of patients to study. Thus, efficient diagnostic criteria are necessary to make the differential diagnosis of a medical condition from the one in which the patients simply prefer to avoid gluten. It is unclear whether gluten triggers symptoms in patients with IBS and the mechanisms by which gluten or other wheat proteins trigger the symptoms in these patients are also not defined. Some patients improve with gluten withdrawal from the diet and return to symptoms after reintroduction. However, eliminating gluten from the diet alone does not seem to be enough to control the symptoms $^{(27,37,44,45,53,58,60,62,66,68,69,71,72,74)}$. In addition, it is also difficult to diagnose overlap with other components of wheat. There is also evidence that IBS symptoms could be triggered by carbohydrate components of fructan and galactans, the FODMAPs. Including lactose, since many foods rich in FODMAPs are also rich in lactose. The FODMAPs are poorly absorbed short chain carbohydrates composed of small osmotically active molecules that can trigger IBS like symptoms by excessive accumulation of fluids and gases, inducing hyper visceral hypersensitivity, changes in intestinal microbiota, and alteration of enteric hormones and neurotransmitters that may explain the generation of symptoms ${ }^{(72-79)}$. In addition, $\alpha$-amylase / trypsin inhibitors (ATIs) have been used in greater amounts to eliminate highly resistant pests and pests in wheat and cereals ${ }^{(75)}$. In view of their inflammatory and immunological potential, they also could be considered as possible inducers of intestinal and extra-intestinal manifestations in patients with CD or IBS ${ }^{(44-47)}$.

In summary, wheat contains more than one potential inductor of IBS symptoms. The similarity of the epidemiological clinical picture of IBS-like disorders, the absence of biomarkers for the diagnosis of IBS and NCGS, combined with the discordant results of the double-blind placebo-controlled trials, hinder to define a culprit. These facts probably create many terms for the same clinical entity.

\section{IV-Clinical and therapeutic aspects of IBS and NCGS overlap}

After the steps of the difficult diagnosis of IBD-like disorders have been overcome, including a clinical evaluation and a rigorous anamnesis, the use of restrictive diets and frequent clinical follow-up are a therapeutic option. A statistically significant clinical improvement has been described in patients with IBS and food intolerance when using restrictive diets. Among the foods reported as being associated with the symptoms of IBS, those high in carbohydrates, gluten and wheat are common. Therefore, a better understanding of the dietary factors involved in IBS and the underlying mechanisms of gluten/wheat/FODMAPs sensitivity are crucial in determining the true benefit of the exclusion diet in
IBS and its subsequent standardization. This effective evaluation could be translated into new and effective new dietary strategies for the management of patients with IBS ${ }^{(71-79)}$.

Double-blind placebo-controlled trials with cross-over trials represent the current gold standard to confirm what would be the dietary factor (s) involved in generating functional symptoms associated with food intolerance in IBS patients and also in those diagnosed as IBS-like -disorder, due to the lack of specificity of the symptoms. Based on the different dietary factors associated with triggering symptoms, patients may be labeled as non-celiac or non-celiac gluten sensitive with sensitivity to wheat proteins or even sensitive to FODMAPs. Diagnostic investigation will be facilitated by both the awareness of these disorders and the careful analysis of the records and food anamnesis. It is important to emphasize that self-report of gluten sensitivity by the patient does not confirm the diagnosis of NCGS and that the prescription of a gluten-free diet for gastrointestinal and other symptoms may lead to underdiagnoses of $\mathrm{CD}^{(80-84)}$. Recently, Picarelli et al. developed an oral mucosal contact test for gluten (GOMPT), which seems to be a reliable and rapid tool to confirm the diagnosis of NCGS, although additional investigations are necessary since the population evaluated was small and the tests performed in a single diagnostic center ${ }^{(44)}$. A diet low in FODMAPs has been suggested as a strategy to improve symptoms in patients with IBS, regardless of the underlying cause. Although a small number of patients, many studies and randomized controlled trials have reported good control of IBS symptoms after a low diet in FODMAPs, with a general improvement in gastrointestinal symptoms in $68 \%-86 \%$ of patients with IBS. In addition, this diet appears to be superior to a gluten-free diet in patients diagnosed with NCGS ${ }^{(85-88)}$. However, identifying the most offensive FODMAPs in specific patients could attenuate dietary restrictions, such as lactose intolerance. In a retrospective case review, symptom improvement was observed in up to $85 \%$ of IBS patients with associated diagnosis of lactose malabsorption. However, prospective studies show that restriction to lactose alone is a trigger for IBS symptoms is not sufficient for the effective relief of symptoms in functional GI disease. Treatment of lactose intolerance should involve reduction of lactose intake rather than exclusion or even enzyme replacement for primary adult lactase deficiency, which has many available diagnostic tests characterized by different principles, availability, sensitivity, specificity, and $\operatorname{cost}^{(50,51,80,84,86,88)}$. Finally, in spite of the controversies, small Intestine Bacterial Overgrowth (SIBO) should always be considered as a differential diagnosis in patients with IBS, since the reported prevalence of SIBO in patients with IBS is generally high, varying from $4 \%$ to $64 \%$ and involving mainly patients with IBS-D. Some studies report that treatment with SIBO seems to be associated with improvement of symptoms in patients with IBS who associate them with food intolerance ${ }^{(80,83,85,86,88)}$

It is also necessary to emphasize that long-term restrictive diets probably have implications for intestinal homeostasis. There is evidence that intensive restriction of FODMAPs and wheat products could have long-term negative consequences, both from the nutritional point of view and the impact on the intestinal microbiota $^{(85,86,88,89)}$. Thus, identifying more offensive FODMAPs in specific patients could mitigate food restrictions, preventing future clinical complications. In relation to the treatment of NCGS many questions remain unanswered and it needs to be verified whether the elimination of dietary gluten alone is sufficient for the control of symptoms, and to understand the overlap with other components 
of wheat ${ }^{(90-93)}$. However, nutritional counseling requires additional financial resources and not all patients will benefit ${ }^{(77,78,79,83)}$. Dietrich et al. ${ }^{(80)}$ analyzed the effect of a low FODMAPs versus a glutenfree diet (GFD) on clinical symptoms, psychological well-being, intestinal inflammation and intestinal integrity and microbiota in NGCS patients. Their reported that both diets caused microbial shifts in all participants, with a greater variability on genus level and metabolisms groups in NCGS patients. Their findings suggest a multifactorial etiology of NCGS due to a functional effect caused by FODMAPs, combined with a gluten-induced mild immune reaction, and an imbalance of the microbiota. Valeur et al. ${ }^{(38,93)}$ have reported that the microbial composition of the intestine may be a tool to identify patients who are likely to respond to dietary restriction of FODMAPs in patients with IBS these findings provide additional information for the study of etiopathogenesis and treatment not only of $\mathrm{CD}$, but also of gastrointestinal disturbances similar to IBS, such as NCGS. The need for better clinical understanding of the nature of NCGS including your trigger, diagnosis, treatment and risks, justify the recent increase in gluten-related diseases research ${ }^{(27,94-96)}$.

\section{CONCLUSION}

The recent increase in scientific research on IBS disorders, such as the NCGS, is visible and justified. The borderline between CD, wheat allergy, IBS and NCGs is not always clearly distinguishable, and the frequency and clinical identity of the NGCS are still unclear. More careful planning of clinical trials will lead to a better understanding of the nature of NCGS and its association with IBS. These future findings may help to establish the magnitude of the problem including triggers, diagnosis, treatment, risks, and implications for human diseases, separating facts from myths.

Soares RLS. Síndrome do intestino irritável, intolerância alimentar e intolerância não celíaca ao glúten. Um novo desafio clínico. Arq Gastroenterol. 2018;55(4):417-22.

RESUMO - Cerca de $80 \%$ dos pacientes com síndrome do intestino irritável (SII) relatam que seus sintomas são desencadeados após a ingestão de um ou grupos específicos de alimentos. Nesse grupo, glúten, trigo e proteínas relacionadas (como inibidores de amilase-tripsina e oligo-di-mono-sacarídeos e polióis fermentáveis (FODMAPs) são os fatores desencadeantes de sintomas mais relevantes da SII, embora o verdadeiro 'culpado(s)' ainda não seja conhecido. O conceito de relação causal entre a ingestão de glúten e a ocorrência de sintomas na ausência de doença celíaca e alergia ao trigo foi denominado sensibilidade ao glúten não celíaca (SGNC). A fronteira clínica entre doença celíaca, alergia ao trigo, SII e SGNC não está claramente distinguível, apesar da sobreposição entre SII e SGNC ser frequentemente relatada na literatura. O conhecimento incompleto da etiopatogenia dessas condições clínicas, a falta de dados sobre sua epidemiologia real, bem como a ausência de um padrão ouro para seu diagnóstico da associação SII/ SGNC, dificultam a compreensão dessa nova entidade. "É de suma importância definir com precisão a interação entre SII, intolerância alimentar e SGNC, já que o papel da dieta no tratamento da SII é uma ferramenta essencial no tratamento de um grande número desses pacientes". A presente revisão tem como objetivo apresentar dados atuais a respeito da interação entre SII, intolerância alimentar e SGNC. Além disso questiona-se, com os dados disponíveis, a sensibilidade ao glúten/trigo/FODMAPs, representa "fato" e não "ficção" na geração de sintomas associados a SII.

DESCRITORES - Síndrome do intestino irritável. Intolerância alimentar. Doença celíaca. Hipersensibilidade a trigo.

\section{REFERENCES}

1. Sperber AD, Demitasse D, Fu kudo S, Gerson C, Goshala UC, Gee KA, et al The global prevalence of IBS in adults remains elusive due to the heterogeneity of studies: a Rome Foundation working team literature review. Gut. 2017;66:1075-82

2. Lovell RM, Ford AC. Global prevalence of and risk factors for irritable bowel syndrome: a meta-analysis. Clin Gastroenterol Hepatol. 2012;10:712-721.e4.

3. Soares RL, dos Santos JM, Rocha VR. Prevalence of irritable bowel syndrome in a Brazilian Amazon community. Neurogastroenterol Motil. 2005; 17:883.

4. Husain N, Chaudhry IB, Jafri F, Niaz SK, Tomenson B, Creed F. A population-based study of irritable bowel syndrome in a non Western population. Neurogastroenterol Motil. 2008;20:1022-9.

5. Devanarayana NM, Rajindrajith S, Pathmeswaran A, Abegunasekara C, Gunawardena NK, Benninga MA. Epidemiology of irritable bowel syndrome in children and adolescents in Asia. J Pediatr Gastroenterol Nutr. 2015;60:792-8.

6. Longstreth GF, Thompson WG, Chey WD, Houghton LA, Mearin F, Spiller RC. Functional bowel disorders. Gastroenterology. 2006;130:1480-91.

7. Schmulson MJ, Drossman DA. What Is New in Rome IV. J Neurogastroenterol Motil. 2017;23:151-63.

8. Tack J, Drossman DA. What's new in Rome IV? Neurogastroenterol Motil. 2017;29.

9. Drossman DA. Rome III: the functional gastrointestinal disorders. Gastroenterology 2006;130:1377-1556. Gastroenterology. 2006;130:1377-90.

10. Drossman DA, Corazziari E, Talley NJ, Funch-Jenesn P, Jansens J, Whitehead WE. Rome II: multinational consensus document on functional gastrointestinal disorders. Gut. 1999;45(Suppl 2):II1-1181.

11. Longstreth GF, Wilson A, Knight K, Wong J, Chiou CF, Barghout V, et al. Irritable bowel syndrome, health care use, and costs: a U.S. managed care perspective. Am J Gastroenterol. 2003;98:600-7.
12. Soares RL. Irritable bowel syndrome: A clinical review. World J Gastroenterol. 2014;20:12144-60.

13. Chang JY, Talley NJ. An update on irritable bowel syndrome: from diagnosis to emerging therapies. Curr Opin Gastroenterol. 2011;27:72-8.

14. Brandtzaeg PE. Current understanding of gastrointestinal immunoregulation and its relation to food allergy. Ann N Y Acad Sci. 2002;964:13-45.

15. Mayer EA, Naliboff BD, Chang L. Basic pathophysiologic mechanisms in irritable bowel syndrome. Dig Dis 2001; 19: 212-218. Aliment Pharmacol Ther. 2005;21:663-76.

16. Mayer EA. Gut feelings: the emerging biology of gut-brain communication. Nat Rev Neurosci. 2011;12:453-66.

17. Eswaran S, Tack J, Chey WD. Food: the forgotten factor in the irritable bowel syndrome. Gastroenterol Clin North Am. 2011;40:141-62.

18. Camilleri M, Lasch K, Zhou W. Irritable bowel syndrome: methods, mechanisms, and pathophysiology. The confluence of increased permeability, inflammation, and pain in irritable bowel syndrome. Am J Physiol Gastrointest Liver Physiol. 2012;303:G775-G785

19. Barbara G. Mucosal barrier defects in irritable bowel syndrome. Who left the door open? Am J Gastroenterol. 2006;101:1295-8.

20. Tanaka Y, Kanazawa M, Fukudo S, Drossman DA. Biopsychosocial model of irritable bowel syndrome. J Neurogastroenterol Motil. 2011;17:131-9.

21. Simrén M, Månsson A, Langkilde AM, Svedlund J, Abrahamsson H, Bengtsson U, Björnsson ES. Food-related gastrointestinal symptoms in the irritable bowel syndrome. Digestion. 2001;63:108-15.

22. Monsbakken KW, Vandvik PO, Farup PG. Perceived food intolerance in subjects with irritable bowel syndrome-- etiology, prevalence and consequences. Eur J Clin Nutr. 2006;60:667-72. 
23. Crowe SE, Perdue MH. Gastrointestinal food hypersensitivity: basic mechanisms of pathophysiology. Gastroenterology. 1992;103:1075-95.

24. Chey WD. Food: The main course to wellness and illness in patients with irritable bowel syndrome. Am J Gastroenterol. 2016;111:366-71.

25. Petitpierre M, Gumowski P, Girard JP. Irritable bowel syndrome and hypersensitivity to food. Ann Allergy. 1985;54:538-40.

26. Petruckevitch A, Barton J, Rona R. A population study of food intolerance. Lancet. 1994;343:1127-30.

27. Soares RLS. Celiac Disease or Gluten Related Disorders? Who Would be the Disease of the Time?. Arq Gastroenterol. 2015;52:165-6.

28. Volta U, Pinto-Sanchez MI, Boschetti E, Caio GP, De Giorgio R, Verdu EF. Dietary triggers in irritable bowel syndrome: Is there a role for gluten. J Neurogastroenterol Motil. 2016;22:547-57.

29. Jun DW, Lee OY, Yoon HJ, Lee SH, Lee HL, Choi HS, et al. Food intolerance and skin prick test in treated and untreated irritable bowel syndrome. World J Gastroenterol. 2006;12:2382-7.

30. Atkinson W, Sheldon TA, Shaath N, Whorwell PJ. Food elimination based on IgG antibodies in irritable bowel syndrome: a randomised controlled trial. Gut. 2004;53:1459-64.

31. Soares RL, Figueiredo HN, Santos JM, Oliveira RF, Godoy RL, Mendonca FA. Discrepancies between the responses to skin prick test to food and respiratory antigens in two subtypes of patients with irritable bowel syndrome. World J Gastroenterol. 2008;14:3044-8.

32. Lind R, Arslan G, Eriksen HR, Kahrs G, Haug TT, Florvaag E, Berstad, A Subjective health complaints and modern health worries in patients with subjective food hypersensitivity. Dig Dis Sci. 2005;50:1245-51.

33. Zar S, Mincher L, Benson MJ, Kumar D. Food-specific IgG4 antibody-guided exclusion diet improves symptoms and rectal compliance in irritable bowel syndrome. Scand J Gastroenterol. 2005;40:800-7.

34. Green PH, Lebwohl B, Greywoode R. Celiac disease. J Allergy Clin Immunol. 2015;135:1099-106

35. Kotze LMS. Celiac disease in Brazilian patients: associations, complications and causes of death. Forty years of clinical experience. Arq Gastroenterol. 2009;46:261-9.

36. Parra-Medina R, Molano-Gonzalez N, Rojas-Villarraga A, Agmon-Levin N, Arango M-T, Shoenfeld Y, et al. Prevalence of Celiac Disease in Latin America: A Systematic Review and Meta-Regression. PLoS ONE. 2015;10:e0124040.

37. Tovoli F, Masi C, Guidetti E, Negrini G, Paterini P, Bolondi L. Clinical and diagnostic aspects of gluten related disorders. World Journal of Clinical Cases: WJCC. 2015;3:275-84.

38. Valeur J, Småstuen MC, Knudsen T, Lied GA, Røseth AG. Exploring Gut Microbiota Composition as an Indicator of Clinical Response to Dietary FODMAP Restriction in Patients with Irritable Bowel Syndrome. Dig Dis Sci. 2018;63:429. 36.

39. Varjú P, Farkas N, Hegyi P, Garami A, Szabó I, Illés A, et al. Low fermentable oligosaccharides, disaccharides, monosaccharides and polyols (FODMAP) diet improves symptoms in adults suffering from irritable bowel syndrome (IBS) compared to standard IBS diet: A meta-analysis of clinical studies. Stengel A, ed. PLoS ONE. 2017;12:e0182942.

40. Laatikainen R, Koskenpato J, Hongisto SM, Loponen J, Poussa T, Hillilä M, Korpela R. Randomised clinical trial: low-FODMAP rye bread vs. regular rye bread to relieve the symptoms of irritable bowel syndrome. Aliment Pharmacol Ther. 2016;44:460-70.

41. Soares RL, Figueiredo HN, Maneschy CP, Rocha VR, Santos JM. Correlation between symptoms of the irritable bowel syndrome and the response to the food extract skin prick test. Braz J Med Biol Res. 2004;37:659-62.

42. Halmos EP, Christophersen CT, Bird AR, Shepherd SJ, Gibson PR, Muir JG. Diets that differ in their FODMAP content alter the colonic luminal microenvironment. Gut. 2015;64:93-100.

43. Makharia A, Catassi C, Makharia GK. The Overlap between Irritable Bowel Syndrome and Non-Celiac Gluten Sensitivity: A Clinical Dilemma. Nutrients. 2015;7:10417-26.

44. Borghini R, Donato G, Alvaro D, Picarelli A. New insights in IBS-like disorders: Pandora's box has been opened; a review. Gastroenterol Hepatol Bed Bench. 2017;10:79-89.

45. Biesiekierski JR, Iven J. Non-coeliac gluten sensitivity: piecing the puzzle together. United European Gastroenterol J. 2015;3:160-5.

46. Chen BR, Du LJ, He HQ, Kim JJ, Zhao Y, Zhang YW, et al. Fructo-oligosaccharide intensifies visceral hypersensitivity and intestinal inflammation in a stress-induced irritable bowel syndrome mouse model. World J Gastroenterol. 2017;23:8321-33.

47. Evans PR, Piesse C, Bak YT, Kellow JE. Fructose-sorbitol malabsorption and symptom provocation in irritable bowel syndrome: relationship to enteric hypersensitivity and dysmotility. Scand J Gastroenterol. 1998;33:1158-63.
48. Liebregts T, Adam B, Bredack C, Röth A, Heinzel S, Lester S, et al. Immune activation in patients with irritable bowel syndrome. Gastroenterology. 2007;132: 913-20.

49. Vernia P, Marinaro V, Argnani F, Di Camillo M, Caprilli R. Self-reported milk intolerance in irritable bowel syndrome: what should we believe? Clin Nutr. 2004;23:996-1000.

50. Dainese R, Casellas F, Mariné-Barjoan E, Vivinus-Nébot M, Schneider SM, Hébuterne X, Piche T. Perception of lactose intolerance in irritable bowel syndrome patients. Eur J Gastroenterol Hepatol. 2014;26:1167-75.

51. Yang J, Fox M, Cong Y, Chu H, Zheng X, Long Y, et al. Lactose intolerance in irritable bowel syndrome patients with diarrhoea: the roles of anxiety, activation of the innate mucosal immune system and visceral sensitivity. Aliment Pharmacol Ther. 2014;39:302-11.

52. Aziz I, Branchi F, Sanders DS. The rise and fall of gluten! Proc Nutr Soc. 2015;74:221-6.

53. DiGiacomo DV, Tennyson CA, Green PH, Demmer RT. Prevalence of gluten-free diet adherence among individuals without celiac disease in the USA: results from the Continuous National Health and Nutrition Examination Survey 2009-2010. Scand J Gastroenterol. 2013;48:921-5.

54. Castillo NE, Theethira TG, Leffler DA. The present and the future in the diagnosis and management of celiac disease. Gastroenterol. Rep. (Oxf.) 2015;3:3-11.

55. Cooper BT, Holmes GK, Ferguson R, Thompson R, Cooke WT. Proceedings: Chronic diarrhoea and gluten sensitivity. Gut. 1976;17:398.

56. Ellis A. Linaker BD. Non-coeliac gluten sensitivity? Lancet. 1978;1:1358-9.

57. Catassi C, Elli L, Bonaz B, Bouma G, Carroccio A, Castillejo G, Cellier C, Cristofori F, deMagistris L, Dolinsek J, et al. Diagnosis of non-celiac gluten sensitivity (NCGS): The Salerno experts' criteria. Nutrients. 2015;7:4966-77.

58. Sapone A, Bai JC, Ciacci C, Dolinsek J, Green PH, Hadjivassiliou M, Kaukinen K, Rostami K, Sanders DS, Schumann M, et al. Spectrum of gluten-related disorders: Consensus on new nomenclature and classification. BMC Med. 2012;10:13.

59. Foschia M, Horstmann S, Arendt EK, Zannini E. Nutritional therapy-facing the gap between coeliac disease and gluten-free food. Int J Food Microbiol. 2016;239:113-24.

60. Silvester JA, Weiten D, Graff LA, Walker JR, Duerksen DR. Is it gluten-free? Relationship between self-reported gluten-free diet adherence and knowledge of gluten content of foods. Nutrition. 2016;32:777-83.

61. Catassi C, Bai JC, Bonaz B, Bouma G, Calabrò A, Carroccio A, et al. Non-Celiac Gluten Sensitivity: The New Frontier of Gluten Related Disorders. Nutrients. 2013;5:3839-53

62. DiGiacomo DV, Tennyson CA, Green PH, Demmer RT. Prevalence of gluten-free diet adherence among individuals without celiac disease in the USA: results from the Continuous National Health and Nutrition Examination Survey 2009-2010. Scand J Gastroenterol. 2013;48:921-5.

63. Catassi C, Elli L, Bonaz B, Bouma G, Carroccio A, Castillejo G, et al. Diagnosis of Non-Celiac Gluten Sensitivity (NCGS): The Salerno Experts' Criteria. Nutrients. 2015;7:4966-77.

64. Volta U, Bardella MT, Calabro A, Troncone R, Corazza GR. An Italian prospective multicenter survey on patients suspected of having non-celiac gluten sensitivity. BMC Med. 2014;12:85

65. Castillo NE, Theethira TG, Leffler DA. The present and the future in the diagnosis and management of celiac disease. Gastroenterol Rep (Oxf) 2015;3:3-11.

66. Golley S, Corsini N, Topping D, Morell M, Mohr P. Motivations for avoiding wheat consumption in Australia: Results from a population survey. Public Health Nutr. 2015;18:490-9.

67. Biesiekierski JR, Peters SL, Newnham ED, Rosella O, Muir JG, Gibson PR. No effects of gluten in patients with self-reported non-celiac gluten sensitivity after dietary reduction of fermentable, poorly absorbed, short-chain carbohydrates. Gastroenterology. 2013;145:320-8.e1-3

68. Van Gils T, Nijeboer P, IJssennagger CE, Sanders DS, Mulder CJJ, Bouma G. Prevalence and Characterization of Self-Reported Gluten Sensitivity in The Netherlands. Nutrients. 2016;8:714.

69. Volta U, Bardella MT, Calabro A, Troncone R, Corazza GR. An Italian prospective multicenter survey on patients suspected of having non-celiac gluten sensitivity. BMC Med. 2014;12:85.

70. Uhde M, Ajamian M, Caio G, De Giorgio R, Indart A, Green PH, et al. Intestinal cell damage and systemic immune activation in individuals reporting sensitivity to wheat in the absence of coeliac disease. Gut. 2016;65:1930-7.

71. Lopez-Gallardo JA, Vergara-Jimenez MJ, Cabrera-Chavez F. Self-reported prevalence of symptomatic adverse reactions to gluten and adherence to gluten-free diet in an adult mexican population. Nutrients. 2015;7:6000-15.

72. Aziz I, Lewis NR, Hadjivassiliou M, Winfield SN, Rugg N, Kelsall A, Newrick L, Sanders DSA. UK study assessing the population prevalence of self-reported gluten sensitivity and referral characteristics to secondary care. Eur J Gastroenterol Hepatol. 2014;26:33-9. 
73. Biesiekierski JR, Newnham ED, Shepherd SJ, Muir JG, Gibson PR. Characterization of adults with a self-diagnosis of nonceliac gluten sensitivity. Nutr Clin Pract. 2014;29:504-9.

74. Wahnschaffe U, Schulzke JD, Zeitz M, Ullrich R. Predictors of clinical response to gluten-free diet inpatients diagnosed with diarrhea-predominant irritable bowe syndrome. Clin Gastroenterol Hepatol. 2007;5:844-50; quiz 769.

75. Zeissig S, Kim SJ, Barisani D, Wieser H, Leffler DA, Zevallos V, et al. Wheat amylase trypsin inhibitors drive intestinal inflammation via activation of toll-like receptor 4. J Exp Med. 2012;209:2395-408.

76. Gibson PR, Shepherd SJ. Food choice as a key management strategy for functional gastrointestinal symptoms. Am J Gastroenterol. 2012;107:657-66,quiz667.

77. Carroccio A, Giambalvo O, Blasca F, Iacobucci R, D'Alcamo A, Mansueto P. Self-Reported Non-Celiac Wheat Sensitivity in High School Students: Demographic and Clinical Characteristics. Nutrients. 2017;9(7).

78. Nijeboer P, Bontkes HJ, Mulder CJ, Bouma G. Non-celiac gluten sensitivity. Is it in the gluten or the grain? J Gastrointestin Liver Dis. 2013;22:435-40.

79. Burden M, Mooney PD, Blanshard RJ, White WL, Cambray-Deakin DR, Sanders DS. Cost and availability of gluten-free food in the UK: In store and online. Postgrad Med J. 2015;91:622-6.

80. Dieterich W, Schuppan D, Schink M, Schwappacher R, Wirtz S, Agaimy A, et al. Influence of low FODMAP and gluten-free diets on disease activity and intestinal microbiota in patients with non-celiac gluten sensitivity. Clin Nutr. 2018. pii: S0261-5614(18)30129-8.

81. El-Salhy M, Ystad SO, Mazzawi T, Gundersen D. Dietary fiber in irritable bowel syndrome (Review). International Journal of Molecular Medicine. 2017;40:607-13.

82. Altobelli E, Del Negro V, Angeletti PM, Latella G. Low-FODMAP Diet Improves Irritable Bowel Syndrome Symptoms: A Meta-Analysis. Nutrients. 2017; 9:940.

83. Cozma-Petrut A, Loghin F, Miere D, Dumitrascu DL. Diet in irritable bowe syndrome: What to recommend, not what to forbid to patients! World J Gastroenterol. 2017;23:3771-83.

84. Dugum M, Barco K, Garg S. Managing irritable bowel syndrome: The low-FODMAP diet. Cleve Clin J Med. 2016;83:655-62.

85. Distrutti E, Monaldi L, Ricci P, Fiorucci S. Gut microbiota role in irritable bowel syndrome: New therapeutic strategies. World J Gastroenterol. 2016;22:2219-41.
86. Vazquez-Roque MI, Camilleri M, Smyrk T, Murray JA, Marietta E, O’Neill $\mathrm{J}$, et al. A controlled trial of gluten-free diet in patients with irritable bowel syndrome-diarrhea: effects on bowel frequency and intestinal function. Gastroenterology. 2013;144:903-11.e3

87. Zanwar VG, Pawar SV, Gambhire PA, Jain SS, Surude RG, Shah VB, et al. Symptomatic improvement with gluten restriction in irritable bowel syndrome: a prospective, randomized, double blinded placebo controlled trial. Intest Res. 2016;14:343-50.

88. Murray K, Wilkinson-Smith V, Hoad C, Costigan C, Cox E, Lam C, et al. Differential effects of FODMAPs (fermentable oligo-, di-, mono-saccharides and polyols) on small and large intestinal contents in healthy subjects shown by MRI. Am J Gastroenterol. 2014;109:110-19.

89. Barrett JS, Gearry RB, Muir JG, Irving PM, Rose R, Rosella O, et al. Dietary poorly absorbed, short-chain carbohydrates increase delivery of water and fermentable substrates to the proximal colon. Aliment Pharmacol Ther. 2010;31:874-82.

90. El-Salhy M, Gundersen D. Diet in irritable bowel syndrome. Nutr J. 2015;14:36

91. Skodje GI, Sarna VK, Minelle IH, Rolfsen KL, Muir JG, Gibson PR, et al. Fructan, Rather Than Gluten, Induces Symptoms in Patients With Self-Reported Non-Celiac Gluten Sensitivity. Gastroenterology. 2018;154:529-39.e2.

92. Staudacher H, Lomer MC, Lindsay JO, Irving PM, Whelan K. The impact of low FODMAP dietary advice and probiotics on symptoms in irritable bowel syndrome: A randomised, placebo-controlled, $2 \times 2$ factorial trial. Gut. 2015;64:A51.

93. Valeur J, Røseth AG, Knudsen T, Malmstrøm GH, Fiennes JT, Midtvedt T, Berstad A. Fecal Fermentation in Irritable Bowel Syndrome: Influence of Dietary Restriction of Fermentable Oligosaccharides, Disaccharides, Monosaccharides and Polyols. Digestion. 2016;94:50-6.

94. Shahbazkhani B, Sadeghi A, Malekzadeh R, Khatavi F, Etemadi M, Kalantri E, et al. Non-Celiac Gluten Sensitivity Has Narrowed the Spectrum of Irritable Bowel Syndrome: A Double-Blind Randomized Placebo-Controlled Trial. Nutrients. 2015;7:4542-54.

95. Mansueto P, D'Alcamo A, Seidita A, Carroccio A. Food allergy in irritable bowel syndrome: The case of non-celiac wheat sensitivity. World J Gastroenterol. 2015;21:7089-109.

96. Pinto-Sánchez MI, Verdú EF. Non-coeliac gluten sensitivity: are we closer to separating the wheat from the chaff? Gut 2016;65:1921-2. 